\title{
Fontes e acervos para a história do trabalho na era digital
}

\section{Sources and collections for Labour History in the digital age}

\section{Deivison Gonçalves Amaral* Fabiane Popinigis**}

\begin{abstract}
O GT Mundos do TRABALHo, registrado junto à ANPUH nacional no ano de 2001, completou 20 anos de existência em 2021. Desde seu registro junto à ANPUH-Brasil, foram organizados simpósios temáticos no campo da história social do trabalho no âmbito dos simpósios nacionais de História, chegando, mais recentemente, a até quatro simpósios no $\mathrm{SNH}$, indicando o crescente interesse de professores, pesquisadores e historiadores pelas temáticas abordadas. Além disso, desde 2002 organizam-se as Jornadas Nacionais de História nos anos pares e, a partir de 2010, o Seminário Internacional Mundos do Trabalho, bianualmente. ${ }^{1}$ Esses encontros permitiram a manutenção, criação e ampliação de redes orgânicas de diálogo e trocas historiográficas no campo, incentivando também a criação de sessões estaduais do GT. O amadurecimento dos debates sobre a história do trabalho fez com que os pesquisadores e pesquisadoras vinculadas ao GT Mundos do Trabalho/ANPUH fundassem, em 2019, a Associação Nacional de História do Trabalho, a fim de fortalecer ainda mais o campo. ${ }^{2}$
\end{abstract}

Em 2020, o seminário deveria ocorrer presencialmente na Universidade Federal Rural do Rio de Janeiro. Porém, devido à grave crise sanitária vivida no mundo todo, o VI Seminário Internacional Mundos do Trabalho/X Jornada Nacional de História do Trabalho foi organizado de forma virtual. O Brasil e o mundo viveram, desde o início de 2020, uma

* Doutor em História Social pela Universidade Estadual de Campinas (Unicamp). Professor do Departamento de História da Pontifícia Universidade Católica do Rio de Janeiro (PUC-Rio). E-mail: deivisonamaral@gmail. com. ORCID: http://orcid.org/0000-0002-3828-2280.

** Doutora em História Social pela Universidade Estadual de Campinas (Unicamp). Professora Adjunta do Departamento de História e Relações Internacionais e do Programa de Pós-Graduação em História da Universidade Federal Rural do Rio de Janeiro (UFRRJ). E-mail: fpopinigis@gmail.com. ORCID: http://orcid. org/0000-0001-5218-0566.

1 Sobre a criação do grupo ver: LONER, B. A. Apresentação. Revista Mundos do Trabalho, Florianópolis, v. 1, n. 1, p. 1-10, 2009.

2 Para mais informações ver o site do GT Mundos do Trabalho: https://gtmundosdotrabalho.org/. 
catástrofe humanitária, com a perda de um enorme número de vidas para a covid-19, com o agravante da crise política no Brasil a partir do golpe de 2016. Sendo assim, este também foi um período de agravamento dos ataques às instituições democráticas e aos avanços sociais alcançados pelos governos anteriores, notadamente a expansão das universidades públicas e as instituições de pesquisa e suas políticas de financiamento. Por isso, queremos enfatizar nosso agradecimento à CAPES e à FAPERJ pela manutenção do apoio aos eventos científicos de forma virtual, que possibilitou a concretização do VI Seminário nessas condições. O evento foi transmitido na página do GT no Facebook e nosso canal do Youtube, entre outubro e dezembro de 2020 , com a apresentação de cinco mesas redondas e uma conferência. $^{3}$

Um dos resultados desse evento é a seção Debates, aqui apresentada, pois a Revista Mundos do Trabalho, criada em 2009, tornou-se o principal locus de debate e de circulação da produção sobre história social do trabalho no Brasil, contando também com a circulação internacional e a autoria de pesquisadores estrangeiros. ${ }^{4}$ Sem dúvidas, a pandemia e as restrições por ela impostas nos levaram a depender ainda mais dos meios digitais e seus recursos de arquivos e fontes para seguir adiante com nossos trabalhos de pesquisa. Pretendemos com isso dar a contribuição para o debate sobre Fontes e acervos para a história do trabalho na era digital.

A virada digital impôs novas questões epistemológicas ao ofício do historiador, especialmente no que se refere às formas de armazenar, tratar e acessar a informação. Desde que computadores passaram a ser utilizados para processamento de dados, o tradicional suporte em papel dos documentos utilizados como fontes históricas foi colocado em xeque. $\mathrm{O}$ advento do mundo da informação digital e a rapidez com a qual as informações circulam graças às tecnologias da informação e da comunicação (TIC) impuseram significativas mudanças às práticas profissionais de historiadores e historiadoras a ponto de falar-se em um novo historicismo. ${ }^{5}$ É essencial, portanto, refletir sobre os impactos da era digital na história - ou da história digital - sobre as formas tradicionais de pesquisa e de narrativas sobre o passado. Atualmente convivem nos meios acadêmicos profissionais que se formaram na era pré-digital, que fizeram a transição adaptativa, e profissionais que já se formaram na era digital. No campo

3 Para assistir as mesas do V Seminário Internacional Mundos do trabalho, acessar o Canal do Youtube do GT Mundos do Trabalho: https://www.youtube.com/channel/UCtYDQ7GR5IsknGIFVAzSTBA. O resultado de uma dessas mesas pode ser acessado na forma do dossiê publicado na REVLATT: POPINIGIS, Fabiane; SOUZA, Robério Santos; MORAES, Renata. Apresentação do dossiê: "Associativismo e experiências negras nas lutas por direitos nos mundos do trabalho". Revista Latinoamericana de Trabajo y Trabajadores, n. 2 , 2021. Disponível em: https://revista.redlatt.org/revlatt.

4 Sobre isso ver: CASTELLUCCI, A.; GERBELLI, C. C.; LACERDA, D. P.; PERUSSATTO, M. K.; SCHEER, M. I.; SILVA, N. G. da. Os êxitos da história social do trabalho. Revista Mundos do Trabalho, Florianópolis, v. 12, p. 1-12, 2020.

5 FICKERS, Andreas. Towards a new digital historicism? Doing history in the age of abundance. In: FICKERS, Andreas; DE LEEUW, Sonja (ed.). Making sense of digital sources. Journal of European History and Culture, v. 1, n. 1, p. 12-18, 2012 apud NOIRET, Serge. História Pública Digital. Liinc em Revista, Rio de Janeiro, v. 11, n. 1, p. 28-51, maio 2015. 
da história, particularmente no Brasil, é possível afirmar que a história pensada digitalmente ainda dá os primeiros passos. A transição adaptativa nos ensinou a utilizar ferramentas computacionais para organizar as várias camadas textuais que antes eram dispostas em fichas, por exemplo. Ou mesmo possibilitou pesquisar arquivos estrangeiros desde o próprio local de residência. No Brasil, o impacto da Hemeroteca Digital da Biblioteca Nacional nas pesquisas históricas é o exemplo mais contundente dessa mudança. A história digital nativa, contudo, pode ir além em todos os aspectos, na conservação e processamento de documentos, na pesquisa, no ensino e na divulgação histórica produzida pelos historiadores de ofício, para citar alguns dos mais importantes. Embora não se trate de criar uma nova operação historiográfica ${ }^{6}$ a priori, certamente há uma transformação no trabalho hermenêutico do historiador, de grande impacto epistemológico. ${ }^{7}$ Como alertou Lara Putnam, é preciso dar visibilidade e quebrar o silêncio sobre os procedimentos metodológicos empregados nas buscas em meios digitais. Do contrário, o risco é possibilitar uma pesquisa crescentemente descontextualizada pelos mecanismos de busca. O debate sobre os impactos dessas mudanças no nosso modo de fazer história, desde os primeiros passos da pesquisa e a análise crítica e heurística da fonte, tão cara à história social, está aberto. ${ }^{8}$ Entretanto, nosso objetivo com esta seção de debates e sua apresentação é refletir sobre as possibilidades abertas pelo mundo da informação digital e enfrentar esses desafios.

Enquanto a história nasceu como uma disciplina que utilizava documentos oficiais como fontes históricas, o campo dedicado à história dos trabalhadores e trabalhadoras precisou criar formas de analisar tais documentos e, além isso, precisou encontrar novas fontes para construir narrativas numa perspectiva que levassem em conta os "de baixo". Historiadores e historiadoras do trabalho já estão acostumados a lidar com arquivos e coleções de documentos mais precárias, fragmentadas e diversificadas do que aquelas tradicionalmente utilizadas por historiadores da política e do Estado, por exemplo. Nesse sentido, o campo da história que se dedica à análise das experiências de trabalhadores e trabalhadoras tem uma característica bastante específica no que tange às coleções documentais que constituem os principais arquivos voltados especificamente ao tema: as principais coleções são oriundas de coleções particulares de militantes. ${ }^{9}$ Seja em papel ou digitalizados e disponibilizados para pesquisa online, jornais, atas de assembleias, coleções de fotografias e outros documentos foram as fontes utilizadas por muitos pesquisadores para contar a história dos trabalhadores e trabalhadoras. A maior parte desses documentos foi "salva" de ser destruída por regimes autoritários ou pela

6 CERTEAU, Michel de. A operação historiográfica. In: CERTEAU, Michel de. A escrita da história. Rio de Janeiro: Forense-Universitária, 1982.

7 BRASIL, Eric; NASCIMENTO, Leonardo Fernandes. História digital: reflexões a partir da hemeroteca digital brasileira e do uso de CAQDAS na reelaboração da pesquisa histórica. Estudos Históricos. Rio de Janeiro, v. 33, n. 69, p. 196-219, 2020.

8 PUTNAM, L. The transnational and the text-searchable: digitized sources and the shadows they cast. The American Historical Review, v. 121, n. 2, p. 377-402, 2016.

9 No Brasil, o Arquivo Edgard Leuenroth/Unicamp é um dos exemplos a serem citados. 
repressão policial aos movimentos de resistência e hoje se encontram em acervos criados especialmente para abrigá-los. Outros correm frequentemente o risco de serem descartados, destruídos ou incinerados e demandam vigilância constante de historiadores, arquivistas e militantes para sua preservação. ${ }^{10}$

Também por isso, na era digital, é preciso pensar em qual tipo de informação poderá ser preservada para no futuro contar a história dos trabalhadores e das trabalhadoras. Por exemplo, em julho de 2020, os entregadores por aplicativos organizaram uma grande greve nacional que protestava contra as condições de trabalho precário a que são submetidos, um tipo de trabalho sem direitos, em que a luta muitas vezes não é contra o patrão, figura inexistente nos moldes tradicionais, mas contra o algoritmo criado por grandes corporações tecnológicas para definir o ritmo e o valor do trabalho. ${ }^{11}$ Em décadas anteriores, uma greve desse porte teria contado com assembleias regionais e nacionais, todas documentadas em atas, panfletos, jornais e outros registros físicos. Essa greve, contudo, foi quase totalmente organizada por trocas de mensagens de aplicativos de comunicação por mensagens, muitas vezes criptografadas de ponta a ponta e com recurso de apagamento automático após a leitura. É certo que há documentação sobre essa greve, mas também é fato que o historiador do futuro, para escrever sobre o movimento, precisará de outros suportes documentais, outros métodos e outras formas de narrar o evento e a experiência dos grevistas. A era digital impõe mais do que aprender a utilizar ferramentas novas - algo decerto essencial -, impõe repensar todo o caminho da produção das representações históricas, desde o documento até a narrativa elaborada.

\section{Quais os desafios e possibilidades a história digital impõe a historiadoras e historiadores, em geral, e ao campo da história do trabalho, particularmente?}

OS DOIS ARTIGOS deste debate ajudam a refletir sobre essa e outras questões que entrecruzam a história do trabalho com a história digital. Alexandre Fortes, no texto intitulado Formando historiadores na era digital: concepções e ferramentas, analisa desafios de renovação do processo de formação de profissionais de história em um contexto global crescentemente marcado pela presença de tecnologias de informação em todas as dimensões da vida social. Para tanto, aproveita a experiência da construção de repositório digital voltado a temáticas de história social da Baixada Fluminense (RIMA/CEDIM/UFRRJ) e, ainda, da experiência de docência de cursos na graduação e na pós-graduação que visavam a treinar e, mais que

10 SPERANZA, Clarice Gontarski; SCHMIDT, Benito; Acervos do Judiciário trabalhista: lutas pela preservação e possibilidades de pesquisa. In: MARQUES, Antonio José; STAMPA, Inez Terezinha. Arquivos do mundo dos trabalhadores: coletânea do $2^{\circ}$ Seminário Internacional O Mundo dos Trabalhadores e seus Arquivos: memória e resistência. Rio de Janeiro: Arquivo Nacional; São Paulo: Central Única dos Trabalhadores, 2012.

11 Disponível em: https://brasil.elpais.com/opiniao/2020-07-25/a-luta-dos-entregadores-de-aplicativo-contra-osalgoritmos-autoritarios.html. 
isso, desafiar estudantes a pensar maneiras de utilizar as ferramentas digitais na produção do conhecimento histórico. Lucas Poy, em artigo intitulado $\mathrm{O} 50^{\circ}$ aniversário da International Association of Labour History Institutions (IALHI) - Seu lugar na história dos arquivos e bibliotecas do movimento operário, analisa as potencialidades das transformações que a era digital propiciou a partir da história de instituições, arquivos e bibliotecas dedicadas à história do movimento operário e das esquerdas e de suas relações internacionais. As instituições ligadas à IALHI tinham atuação limitada geograficamente à Europa e, com a digitalização de acervos e, especialmente, compreensão dos recursos que a era digital propiciava, conseguiu expandir seu campo de atuação para a América do Norte e América do Sul. Em conjunto, os dois textos permitem a reflexão sobre os desafios a serem enfrentados, mas também sobre as possibilidades que a história digital abre ao campo da história do trabalho.

A era digital criou muitas ferramentas novas e, sem dúvida, poucas delas são exploradas atualmente. Basta ver quantos cursos de graduação em História no Brasil têm disciplinas sobre história digital, humanidades digitais, técnicas de criação de conteúdo digital na internet, técnicas de pesquisa em meio digital, mineração de dados, criação de exposição on-line, criação de georreferenciamento, entre outras coisas. Ao terminar a leitura da frase anterior, o leitor ou a leitora deve ter parado para pensar e, com sorte, lembrou-se de um exemplo de curso que conte com alguma das indicações de disciplinas técnicas referidas. É urgente pensar nisso como algo incontornável ao nosso campo.

Trata-se apenas de fazer história com métodos usuais, mesmo que com ferramentas digitais, e divulgá-la digitalmente? Ou utilizar novos métodos e novas ferramentas para fazer história sob novas bases epistemológicas? Pensar em formas de fazer a história digitalmente significa mais que aprender a utilizar ferramentas para facilitar velhos métodos. São novas possibilidades de pesquisa, novos objetos, novas fontes, novos métodos. Especialmente, são novas formas de divulgar e de interagir com os públicos, agora não apenas leitores, mas consumidores do conhecimento que deve ser apresentado em várias linguagens. $A$ própria centralidade da narrativa textual está em questão. Em um mundo em que a audiência contada em curtidas e compartilhamentos parecem conferir mais autoridade do que aquela gerada pelo saber acadêmico, é preciso ocupar espaços na internet e nas redes sociais com o conhecimento produzido academicamente, mas adaptado às novas linguagens. Os livros e artigos são essenciais para a qualidade do que é produzido na pesquisa científica, mas só cumprem parte da tarefa de comunicar o conhecimento. Não por acaso, em programas de pós-graduação em história digital, dissertações e teses não são necessariamente entregues em formato de um texto encadernado e podem apresentar formatos de websites, softwares, mapas de georreferenciamento, videodocumentários, podcasts etc. ${ }^{12}$ Tudo isso impacta na

12 Um exemplo na Europa é o The Luxembourg Centre for Contemporary and Digital History $\left(\mathrm{C}^{2} \mathrm{DH}\right)$, da Universidade de Luxemburgo. Disponível em: https://www.c2dh.uni.lu/. 
relação entre historiadores e seus públicos. Do arquivo ao método de pesquisa, da narrativa ao formato da apresentação e divulgação, há muitas novas possibilidades.

Se na origem do campo da história do trabalho, os primeiros grandes arquivos foram oriundos de coleções particulares de militantes, na era digital, a coleta e a produção de fontes históricas podem continuar a seguir esse padrão. Os arquivos podem ser colaborativos e resultantes da interação entre profissionais (historiadores, arquivistas etc.) e os próprios trabalhadores e trabalhadoras. A pandemia da covid-19, por exemplo, forçou o exercício de pesquisar, ensinar e divulgar conhecimento histórico on-line como nunca fora experimentado. São inúmeros os projetos que fizeram uso de recursos digitais para criar plataformas colaborativas. A título de exemplo, a Federação Internacional de História Pública mapeou e georreferenciou centenas de projetos surgidos para registrar experiências com a pandemia. São projetos variados que coletaram documentos, fotos, testemunhos orais (em áudio ou vídeo) e escritos, em plataformas colaborativas. Em essência, os recursos digitais foram utilizados para documentar, registrar memórias e para criar fontes históricas. Um recurso como esse, por exemplo, poderia ter registrado no calor do momento e com mais detalhes as negociações de pauta, os arranjos políticos e as estratégias de luta dos referidos entregadores por aplicativos em greve. Abre-se, portanto, a possibilidade de criar arquivos colaborativos com os trabalhadores e trabalhadoras, no qual memórias e experiências de luta possam ser colecionadas.

Recentemente, outras experiências importantes surgiram no Brasil e fizeram uso de ferramentas digitais para produzir conteúdo histórico, de divulgação científica, para ampliar o campo de alcance da produção muitas vezes restrita a especialistas e interferir no debate público. ${ }^{13}$ É verdade que ainda são os primeiros passos, mas os exemplos acima e os apontamentos dos artigos desse debate indicam a grande potencialidade aberta pelo mundo digital para historiadores e historiadoras.

Há uma revolução digital em curso.

Está aberto um mundo digital de possibilidades.

Recebido em 08/12/2021

Aprovado em 10/12/2021

13 Ver, por exemplo, duas iniciativas que têm dado excelentes resultados e de grande alcance: o projeto do Laboratório de Estudos de História dos Mundos do Trabalho (LEHMT/UFRJ) e o projeto Salvador Escravista. Em suas várias seções, o site do LEHMT apresenta artigos, vídeos, podcasts, planos de atividades didáticas e um mapeamento de lugares de memórias dos trabalhadores. Esta última seção é exemplo das potencialidades das ferramentas digitais e, especialmente, das TIC para o campo da história do trabalho. A seção, que apresenta artigos e um georreferenciamento dos lugares de memória dos trabalhadores, foi iniciada com demandas dos editores do site e, uma vez divulgada, começou a receber ofertas dos leitores. Disponível em: https://lehmt.org/. Acesso em: 23 nov. 2021.

O projeto Salvador Escravista, por sua vez, surgiu durante o movimento mundial chamado Vidas Negras Importam, surgido após o brutal assassinato do afro-americano George Floyd pela polícia de Minneapolis (EUA), que desencadeou como uma das reações dos movimentos antirracistas, a intervenção em monumentos que homenageavam escravistas. Nesse sentido, mapeou e georreferenciou homenagens reparadoras e controversas, lugares de memória e lugares esquecidos. Disponível em: https://www.salvadorescravista.com/ mapa. Acesso em: 23 nov. 2021. 